\title{
SUMINISTRO DE DOCUMENTOS: COSTES Y PRECIOS
}

\section{Vázquez Valero*}

Resumen: Se examinan los costes directos e indirectos generados en el suministro de documentos primarios, tanto en el caso de reproducción como de préstamo, así como las posibles opciones que se pueden establecer para la financiación de dichos costes, indicando las ventajas e inconvenientes de cada una de ellas. Despues de exponer la normativa legal vigente sobre el cobro de servicios públicos, se recoge en una tabla la gama de valores máximos y mínimos en la que oscilan las tarifas aplicadas por unas 500 bibliotecas españolas. Los datos aportados destacan la necesidad de coordinación entre esas bibliotecas, a fin de homogeneizar tanto las tarifas como las modalidades de pago y petición.

Palabras clave: Suministro de documentos, costes, tarifas, España.

Abstract: Direct and indirect costs produced by the document supply, both for reproduction and loan, are examined together with possible financing options, their advantages and disadvantages. After describing the current legal situation of public services charges in Spain, the maximum and minimum fees for interlending activities of about 500 Spanish libraries are presented. The data emphasize the need of coordination between libraries in order to unify both fees and methods of request and payment.

Keywords: Document supply, costs, fees, Spain.

\section{Introducción}

Las actividades de préstamo y suministro de documentos son actualmente un elemento esencial de los servicios bibliotecarios. Sin embargo, antes de la II Guerra Mundial eran consideradas actividades extra u opcionales, pues cualquier biblioteca consideraba un fallo tener que conseguir un documento por estos procedimientos (1). Ahora, todas las bibliotecas, incluso las más grandes, aceptan que no pueden ser autosuficientes y prácticamente todas obtienen documentos de otras bibliotecas.

El acceso gratuito a la información ha sido siempre una meta hacia la que ha tendido el mundo bibliotecario; sin embargo, hay que tener presente que el que una actividad sea gratuita no quiere decir que no genere costes.

\section{La transferencia de la información y el acceso al documento primario}

La transferencia de información implica a múltiples agentes y ocasiona gastos en diversas etapas del proceso. Las consultas a bases de datos bibliográficas son hoy el medio más usual de obtener referencias de trabajos sobre un tema dado, a un coste relativamente módico. Los documentos relativos a esas referencias deberán después de ser localizados para su examen. En esta etapa de la transferencia

* CINDOC -CSIC.

Recibido 6-9-94. 
de información hay que tener presente el hecho de que ninguna biblioteca, por importantes que sean sus colecciones, puede atender con sólo sus fondos la demanda potencial de sus usuarios. En muchos casos será necesario conseguir en otra biblioteca un documento solicitado por un usuario a través de préstamo interbibliotecario, que no es otra cosa que un sustituto de la adquisición del documento (2) y lo motivan tres posibles causas diferentes:

1. El documento no está disponible en las librerías.

2. El documento no se puede adquirir en un periodo de tiempo aceptable por el usuario.

3. El uso previsto del documento es demasiado bajo comparado con su coste.

A la biblioteca que posee el documento, su suministro, bien sea en forma de fotocopia o en préstamo, le origina unos gastos. Surge entonces la cuestión de quién debe pagar estos gastos.

En el siglo XIX, cuando se establecieron las prácticas del préstamo interbibliotecario, se cometió el error de suponer que se produciría una reciprocidad de transacciones entre centros, no se pensó que podria haber bibliotecas que tendrian el papel de suministradoras netas y otras que serian por el contrario casi exclusivamente peticionarias (3). Este desequilibrio ha sido posiblemente la principal causa de que se suscitara la cuestión del cobro por estos servicios y de quién tiene que soportar sus costes.

\section{Costes del suministro de documentos}

Si hay que cobrar, la primera cuestión planteada será cómo debe calcularse el precio. Puesto que los costes de adquisición, catalogación, almacenamiento y conservación deben ser soportados en cualquier caso por la biblioteca suministradora, solamente los costes directamente relacionados con el préstamo o suministro de documentos serán tenidos en consideración. La principal dificultad es que estos costes son a veces dificiles de evaluar y pueden variar mucho de una biblioteca a otra, en función de su organización interna.

Los costes que ocasiona la actividad de préstamo interbibliotecario son de dos tipos:

- Costes directos: Generados en el desarrollo de la actividad; incluyen costes de personal, de material y de mantenimiento.

- Costes indirectos: No se producen especificamente durante el desarrollo de la actividad pero son soportados por la biblioteca que la realiza (electricidad, teléfono, gastos de instalación, local, etc.).

La línea divisoria entre costes directos e indirectos no siempre es clara; por ejemplo, el alquiler o la tasa de amortización de una fotocopiadora habrá que 
incluirlo en una u otra categoria según que la máquina se dedique exclusivamente al servicio de reproducción de documentos o para actividades administrativas, pero cuando la máquina se utiliza para ambas tareas, será preciso repercutir dicho coste en relación con el uso que se haga en cada actividad.

Desglosados por tareas, estos costes están integrados por:

- Costes de localización y manejo: Incluyen los relativos al coste del personal necesario para la localización topográfica del documento, desplazamiento a la zona de reproducción y colocación posterior en su sitio.

- Costes de reproducción: Se obtienen multiplicando el coste unitario de reproducción por página, por el número de páginas.

- Costes de envio: Engloban los costes generados por el embalaje, tasas de correo y facturación.

Los gastos antes mencionados son los producidos a la biblioteca que posee el documento, a ellos habrá que añadir los ocasionados a la biblioteca solicitante que incluyen los de localización en catálogos, petición a la biblioteca que lo posee, recepción y envio al usuario final.

Estos son los gastos relativos a la obtención de copias de documentos. Cuando se trata de préstamos hay una composición ligeramente diferente de los costes.

Para la biblioteca solicitante:

Localización en catálogos.

Solicitud (correo postal, fax, correo electrónico, etc.).

Recepción del documento.

Aviso al usuario final (generalmente por teléfono).

Reexpedición del documento (embalaje y tasas postales).

Para la biblioteca prestataria:

Localización topográfica.

Expedición (embalaje y envio).

Registro del préstamo (y reclamación en su caso).

Recepción del material devuelto.

Colocación del material.

Los gastos de correo y embalaje son en general más altos que en el caso de material fotocopiado.

Muchos de estos costes están incluidos en las operaciones generales de una biblioteca y no se cargan en la actividad de préstamo interbibliotecario. Si se hiciera asi, el coste total de cualquier transacción bibliotecaria seria considerablemente más alto que cualquiera de las tarifas que actualmente se aplican (4).

\section{4 ¿Quién debe pagar?}

Al hacer frente a estos costes, los gestores de las bibliotecas podrian considerar tres posibles fuentes de financiación: 
1. La Administración: Al ser la mayoria de las bibliotecas dependientes de organismos oficiales, no cabe duda que la Administración subvenciona parcialmente el proceso, a través de los costes de desarrollo y mantenimiento de los catálogos colectivos, adquisición de colecciones, establecimiento de tarifas postales reducidas, etc. En algunos paises, hay también una participación mayor de la Administración a través de la existencia de un Servicio Nacional de Préstamo.

2. La biblioteca prestataria: Se podría optar por elegir la vía más social de asumir todos los costes implicados en el proceso de préstamo, con cargo al presupuesto de la biblioteca que lo realiza. Esta política también puede ser objetada: imaginemos que una biblioteca A suministra gratis una demanda de información procedente de otra biblioteca B para un usuario de esta última. Una parte importante del coste que este suministro ocasiona lo está asumiento con cargo a su presupuesto la biblioteca $\mathrm{A}$ para un usuario que no es suyo. Imaginemos también que la biblioteca $\mathrm{A}$ ha sido fuertemente subvencionada, mientras que la administración de la que depende la biblioteca $\mathrm{B}$ ha priorizado otras actividades en vez de las bibliotecas; un ciudadano de la administración de que depende A podria no estar conforme con que parte de sus impuestos se destinaran a dar servicio a un ciudadano de otra administración con distinta política cultural.

3. La biblioteca solicitante: Esta opción hace recaer el coste en la biblioteca beneficiaria del préstamo, que tendrá a su vez su propia política de cobrar o no al usuario final.

El programa de Disponibilidad Universal de las Publicaciones (DUP) (5), patrocinado por la IFLA y la UNESCO, desarrolla recomendaciones destinadas a:

Facilitar la accesibilidad de los usuarios de cualquier pais a la totalidad de las publicaciones, independientemente del país en que hayan sido producidas.

El programa DPU establece que:

La disponibilidad se asegura principalmente a través de las bibliotecas.

e indica que:

Puesto que ninguna biblioteca ni organización puede actualmente satisfacer con sus propios recursos todas las necesidades de información de sus usuarios. habrán de idearse los medios para obtener en otros lugares las publicaciones demandadas.

Asimismo, el programa incluye recomendaciones sobre la necesidad de establecer sistemas de préstamo interinstitucional y sobre la disponibilidad internacional, resaltando que:

Todos los paises deherian estar en condiciones de suministrar sus propias publicaciones al resto del mundo, mediante préstamo o reproduccion. siempre que se ajuste a la legislación vigente en materia de derechos de autor. 
Con respecto al pago de estos servicios, el programa DUP sólo recomienda que se hagan

en un plazo razonable y con un coste mínimo.

Sobre las tres posibles fuentes de financiación del préstamo interbibliotecario antes mencionadas existen algunas razones positivas que apoyan la última alternativa, es decir, que el coste recaiga sobre la biblioteca solicitante (6).

Primero, permite una contabilidad real, pues si las bibliotecas solicitantes descargan parte del coste del servicio que dan, a otra biblioteca, deja de conocerse el coste real de dicho servicio y se engañan a sí mismas y a las autoridades que las financian en cuanto a los gastos verdaderos de su funcionamiento.

Segundo, funcionar con costes reales permite a las bibliotecas sopesar la actividad de préstamo frente a la de compra. Haber pagado varias veces a una biblioteca por obtener copias de artículos de una misma revista, puede decidir a la biblioteca peticionaria a suscribirse a ella.

Tercero, obtener dinero por el suministro de documentos permitirá a las bibliotecas prestatarias mejorar la eficacia de este servicio que tanta mano de obra requiere, y también evitará la necesidad de reducirlo si la demanda recibida es superior a la que esa biblioteca puede asumir con los medios de que dispone.

Cuarto, recibir dinero por el servicio puede animar a las pequeñas bibliotecas a incorporar sus fondos a los sistemas de préstamo. Los catálogos colectivos nacionales, si están provistos de un módulo de préstamo, podrian desviar las peticiones hacia esas pequeñas bibliotecas, cuando correspondan a títulos existentes en ellas, aunque también se encuentren en bibliotecas mejor provistas, dando lugar a un reparto de tareas que favorecerá la eficacia del conjunto nacional.

\section{Derechos de reproducción}

En los costes enumerados que el suministro de documentos genera, no están incluidos los derechos de reproducción o copyright que la copia de algunos documentos devenga.

Hay una creciente tendencia en diversos paises hacia una legislación más rectrictiva sobre los derechos de copia. En España, la ley actualmente vigente (7) contiene un artículo, el 25 , que ha sido modificado en dos ocasiones desde la promulgación de la misma el 11 de noviembre de 1987, y que incide directamente en la actividad de reproducción que se lleva a cabo en los servicios de suministro de documentos. Dicho articulo modificado señala que:

La reproducción, exclusivamente para uso privado, por medio de aparatos o instrumentos técnicos no tipográficos, de obras publicadas en forma de libros o publicaciones que a estos efectos se asimilen reglamentariamente. originara una remuneración dirigida a compensar anualmente los derechos de propiedad intelectual dejados de percibir por razón de la expresada reproducción. Esta remuneración se determinará en función de los equipos, aparatos y materiales idóneos para realizar dicha reproducción, fabricados en territorio español o adquiridos fuera 
del mismo para su distribución comercial o utilización dentro de dicho territorio en el periodo anual correspondiente. Este derecho se hará efectivo a través de las entidades de gestión de los derechos de la propiedad intelectual.

No obstante, más adelante, el artículo 37 de dicha ley establece que:

Los titulares de los derechos de autor no podrán oponerse a las reproducciones de las obras cuando aquéllas se realicen sin finalidad lucrativa por los museos, bibliotecas, fonotecas, filmotecas, hemerotecas o archivos, de titularidad pública o integradas en instituciones de carácter cultural o cientifico y la reproducción se realice exclusivamente para fines de investigación.

Este articulo aparentemente deja fuera del ámbito de aplicación de la ley el suministro de documentos tal como se realiza en las bibliotecas. Por otra parte, aunque la mayor proporción de la demanda recibida en los servicios de suministro se refiere a artículos de revistas, cuya peculiaridad no está contemplada ni definida en esta ley, es cierto que la tendencia en muchos paises es a proteger la reproducción de muchas revistas científicas, por lo que en estos casos en el coste de obtención de la copia de un artículo a partir de ellas, habrá que incluir un canon de reproducción.

\section{Cuantía de las tarifas}

Es importante aclarar la diferencia entre el coste de una actividad y su precio; el coste se refiere a los gastos producidos para poder realizar una determinada actividad, mientras que el precio es la cifra que se cobra al usuario por ella. Frecuentemente el precio cobrado por el suministro de documentos guarda poca relación con lo que cuesta (8). La cuestión no es recuperar la totalidad de los costes generados, sino más bien obtener una compensación siginificativa.

El pago de los servicios tropieza de ordinario con el hecho de que la mayor parte de las unidades de información pertenecen a organismos públicos, cuyos servicios, según algunos, deben ser gratuitos. Sin embargo, constantemente comprobamos que no todos los servicios públicos son, al menos totalmente, gratuitos.

En España, el coste de los servicios públicos viene regulado por la Ley 8/1989 referente al régimen jurídico de las tasas y los precios públicos (9). Esta ley en su artículo 13 indica claramente que:

Podrán establecerse tasas por la prestación de servicios, tales como:

b) expedición de documentos a instancias de parte.

$\cdots$

h) servicios académicos y complementarios,

i) servicios o actividades que beneficien a personas o hayan sido motivadas por éstas.

En cuanto al devengo del coste, el articulo 15 señala que:

podrá devengarse cuando se presente la solicitud que inicie la actuación. que no se realizará o tramitará sin que se haya efectuado el pago correspondiente. 
Con respecto a los elementos a tener en cuenta en la fijación de las tasas, el artículo 19 señala que:

1) El importe de las tasas no podrá exceder del coste real o previsible del servicio.

2) Para la determinación de la cuantia de las tasas se considerarán los gastos directos $e$ indirectos que se generen en el servicio.

Por último, con respecto a la cuantía, el artículo 25 especifica:

1) Los precios públicos se establecerán a un nivel que cubra como mínimo los costes económicos originados por la prestación del servicio.

2) Cuando existan razones sociales, benéficas, culturales o de interés público que asi lo aconsejen, podrán señalarse precios públicos que resulten inferiores a los parámetros previstos en el apartado anterior, previa adopción de las previsiones presupuestarias oportunas para la cobertura de la parte del precio subvencionada.

Es claro que, habida cuenta de lo expuesto en la ley, la mayoria, si no todas las tarifas aplicadas por las bibliotecas españolas tiene en cuenta lo recomendado en el apartado 2 de este artículo.

\section{Situación en Espafia}

A pesar de las ventajas de obtener una compensación económica por estos servicios, la aplicación del cobro en las diversas bibliotecas ha tenido lugar de forma irregular, sin que haya habido de forma general acciones de coordinación en relación con la cuantía de las tarifas, las modalidades de pago, e incluso los modelos de impresos de petición utilizados. Esto, que en términos generales ocurre a nivel mundial, se da también en España.

Las tarifas que aplican las bibliotecas españolas corresponden a tres modalidades:

- Por página fotocopiada; dentro de las que aplican esta modalidad, algunas cargan parte de los gastos de envío y otras no.

- Por bloques de 5 o de 10 páginas. En este caso, hay también diferencias tanto en el número de páginas de los bloques, como en el precio igual o diferente del primer bloque y los bloques sucesivos.

- Mixta, es decir, hay un coste minimo que cubre la reproducción de un documento de hasta un número dado de páginas, $\mathrm{y}$ a partir de ese número se aplica un precio por página fotocopiada adicional.

En todas las modalidades hay una gran diversidad de precios. La tabla adjunta muestra las tarifas máximas y mínimas actualmente vigentes en un grupo de unas 500 bibliotecas españolas que colaboran con el CINDOC en el servicio de suministro de documentos. 
Tabla I

Tarifas máximas y mínimas aplicadas por las bibliotecas españolas en el suministro de documentos

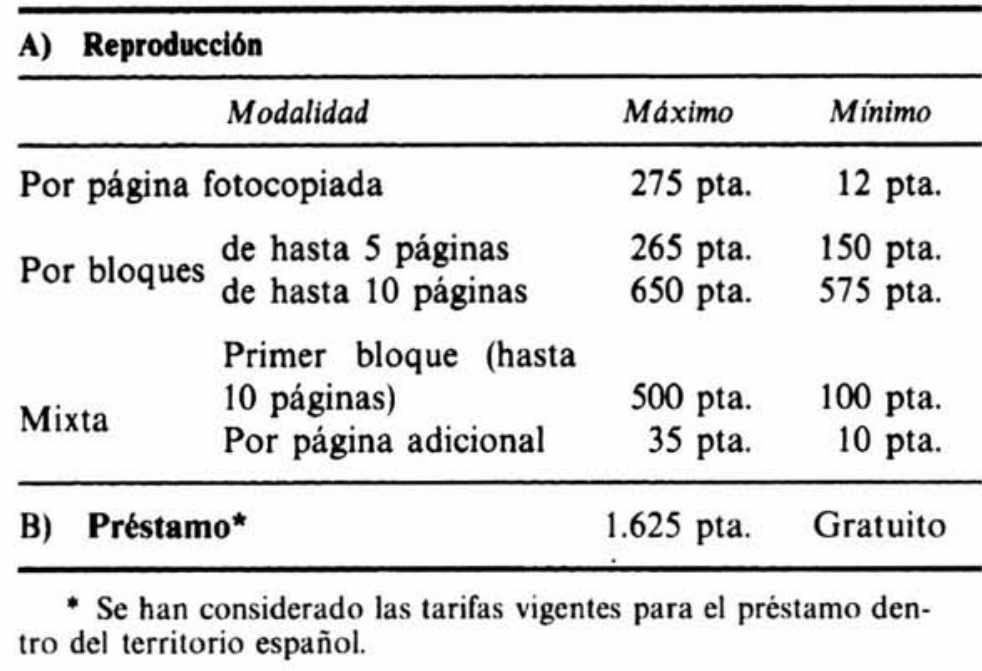

En cuanto a las modalidades de pago establecidas existen también diferencias entre unas bibliotecas y otras. La mayoría requiere el pago previo que puede realizarse en forma de un depósito en metálico a favor de la biblioteca prestataria, del que se va descontando la cuantía correspondiente a los sucesivos envíos, o mediante cupones o bonos que las bibliotecas proporcionan previo pago. El precio de un cupón corresponde, en general, a la reproducción de un documento de hasta 5 ó 10 páginas.

Hay también bibliotecas que mantienen el pago contra reembolso y aún otras que envían presupuesto del coste de cada trabajo solicitado y sólo cuando han recibido el importe proceden a realizar su reproducción.

Con respecto al préstamo de libros hay que indicar que algunas bibliotecas suministran documentos en forma de fotocopias pero no libros en préstamo. Entre las que dan este servicio las diferencias son muy grandes, pues hay bibliotecas en que es totalmente gratuito, algunas sólo cobran gastos de envio, y en las que tienen establecidas tarifas, éstas oscilan entre 575 y 1.625 pta. Hay también alguna biblioteca que exige un depósito en metálico, reintegrable cuando se devuelve el libro.

Es a todas luces evidente que sería deseable la unificación de tarifas y la homogeneización de las modalidades de pago. Por supuesto que se requerirán negociaciones y habrá que hacer concesiones por unos y por otros.

En algunos países ya se han establecido mecanismos de pago únicos para el préstamo interbibliotecario (4). Así, en el Reino Unido los pagos entre bibliotecas suelen hacerse con cupones del Centro de Suministro de Documentos de la Biblioteca Británica. También las bibliotecas médicas suizas uitlizan para el pago de sus transacciones los cupones emitidos por la Asociación de Bibliotecas Médicas Suizas. Cuando alguna biblioteca lo desea, puede recibir de la Asociación el importe en metálico correspondiente a los cupones que posea.

En España, algunas bibliotecas que tienen mucha demanda de préstamo interbibliotecario han establecido sistemas de cuenta de compensación con bibliotecas que actúan indistintamente como prestatarias y como peticionarias. Este sistema 
simplifica mucho la gestión de los cobros ya que la biblioteca deudora sólo necesita efectuar los pagos unas o dos veces al año, según se pacte.

\section{Conclusión}

El pago de los servicios de préstamo interbibliotecario, sobre todo cuando se trata del envio de la reproducción de un documento, es hoy una práctica habitual. Los usuarios, sobre todo cuando trabajan en actividades productivas, están dispuestos a pagar incluso un precio elevado por la información que necesitan, cuando la han recibido oportunamente.

Por otra parte, el pago de un servicio es una medida sencilla y eficaz de comprobar su utilidad. De todas maneras, conociendo el valor de la información y el coste que su obtención implica, sería deseable que las bibliotecas dispusieran de recursos (sobre todo de personal y medios materiales) suficientes, para que el precio que el usuario final tenga que pagar no pueda nunca ser un elemento disuasorio del acceso a la información.

\section{Bibliografia}

1. LINE, M. B. Interlending and Document Supply in a Changing World. International Forum on Information and Documentation (1989), 14(3), 23-24.

2. HUSTACHE, E. Free or fee: the changing debate. Proceedings of the First International Conference on Interlending and Document Supply, Londres 1988, 86-88.

3. LINE, M. B. The principles of cost recovery for international loans. IFLA Journal (1976), 2(2), 81-85.

4. CORNISH, G. P. Feasibility of a Voucher Scheme to Pay for International Interlibrary Transactions. UNESCO PGI-92/WS/5.

5. Congreso Internacional sobre la Disponibilidad Universal de las Publicaciones, UNESCO-IFLA, PGI-82/UAP/2.

6. STUART-STUBBS, B., y RICHARDSON, W. D. Interlibrary Loan Charges: the Arguments for and against. Interlending and Document Supply (1984), 12(1), 3-10.

7. Ley de Propiedad Intelectual (Ley 22/1987 y Ley 20/1992), BOE núm. 275/1987, págs. 24163-34176, y núm. 168/1992, págs. 24125-24128.

8. SMITH, M. Cost of Interlibrary Lending. Interlending and Document Supply (1984), 12(2), 38-39.

9. Ley 8/1989 sobre Tasas y Precios Públicos, BOE (1989), 89-90, 2803-2809. 